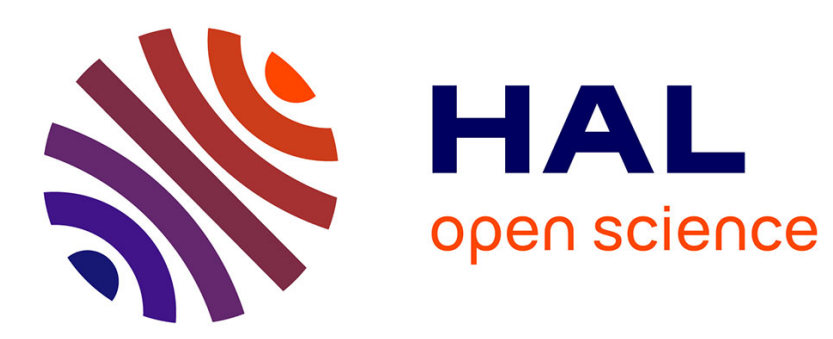

\title{
PLENARY SESSIONMatter transport in ionic crystals P. Jacobs
}

\section{To cite this version:}

P. Jacobs. PLENARY SESSIONMatter transport in ionic crystals. Journal de Physique Colloques, 1980, 41 (C6), pp.C6-207-C6-212. 10.1051/jphyscol:1980653 . jpa-00220091

\section{HAL Id: jpa-00220091 https://hal.science/jpa-00220091}

Submitted on 1 Jan 1980

HAL is a multi-disciplinary open access archive for the deposit and dissemination of scientific research documents, whether they are published or not. The documents may come from teaching and research institutions in France or abroad, or from public or private research centers.
L'archive ouverte pluridisciplinaire HAL, est destinée au dépôt et à la diffusion de documents scientifiques de niveau recherche, publiés ou non, émanant des établissements d'enseignement et de recherche français ou étrangers, des laboratoires publics ou privés. 


\title{
PLENARY SESSION.
}

\section{Matter transport in ionic crystals}

\author{
P. W. M. Jacobs $\left(^{*}\right)$ \\ Department of Chemistry, University of Western Ontario, London, Ontario N6A 5B7, Canada
}

\begin{abstract}
Résumé. - L'analyse des mesures de transport sur les cristaux ioniques en termes de modèles des défauts est simplifiée si quelques paramètres des défauts peuvent être connus par d'autres expériences, comme les mesures NMR, ou par des calculs théoriques. Ce papier démontre que le calcul des paramètres des défauts ponctuels est très utile pour la résolution de plusieurs problèmes de transport dans les halogénures alcalins et d'argent. La croissante concurrence entre les résultats des analyses fondées sur les mesures macroscopiques (conductivité ionique) et microscopiques (NMR) est montrée en se référant aux résultats sur les cristaux qui ont la structure de la fluorite.

Abstract. - The analysis of transport measurements on ionic crystals in terms of defect models is facilitated if some of the defect parameters can be determined from separate experiments, such as NMR measurements, or from theoretical calculations. This paper shows how the calculation of point defect parameters has proved useful in resolving a number of transport problems in the alkali and silver halides. The growing measure of concurrence between the results of analyses based on macroscopic (ionic conductivity) and microscopic (NMR) measurements is illustrated by reference to results for crystals with the fluorite structure.
\end{abstract}

1. Introduction. - The traditional macroscopic methods of studying the isothermal transport of matter in ionic crystals are the measurements of ionic conductivity $(\sigma)[1]$ and of diffusion coefficients $(D)$ by tracer [2] or exchange [3] techniques. These data can then be analyzed in terms of one or more defect models $[4,5]$ when agreement between calculated and experimental values of $\sigma$ or $D$ provides both confirmation of the validity of the model used and numerical values for the defect parameters viz. the enthalpies and entropies of defect formation, migration and association. Ionic conductivity runs should generally comprise something between 100 and 200 measurements taken from the precipitation temperature up to as close to the melting point as possible [6] although experimental difficulties caused by sublimation [7], deformation [8], or reaction of the crystal [9] may prevent the full exploitation of this ideal range. It is not feasible to obtain the same high density of data in diffusion measurements. The in troduction of nonlinear least squares analysis $[4,10]$ of conductivity measurements revealed the inadequacy of simple defect models for the alkali halides. Although consistent analyses of conductivity and diffusion data are possible [5] when the measurements are confined to the temperature-range of intrinsic defect disorder, a determination of defect parameters from conductivity measurements over the whole temperature range, with the aid of the traditional Schottky model, leads to values for the anion migration parameters that

(*) Member, Centre for Interdisciplinary Studies in Chemical Physics, University of Western Ontario. are inconsistent with those determined from diffusion measurements [7]. The reason for this is not hard to see. Alkali halide crystals generally contain an excess of divalent cation impurities like $\mathrm{Ca}^{2+}$ so that the conductivity in the extrinsic temperature range is dominated by the motion of cation vacancies. The cation migration and association parameters are therefore determined very precisely. An analysis of the whole conductivity curve using an imperfect model thus forces the parameters for the minority carriers - the anion vacancies - to assume incorrect values. If these are constrained to values consistent with diffusion measurements, then the Schottky defect formation parameters assume unrealistically high values. One of the principal difficulties about the non-linear least squares analysis of conductivity data is the high correlation that exists between some parameters. The use of more elaborate defect models inevitably means the introduction of more parameters with the result that the whole procedure tends to become rather intractable. There are two main ways out of this dilemma. One is to exploit selective doping that will accentuate one or more transport mechanisms at the expense of others, so that the precise value of the defect parameters corresponding to the latter have little effect and they may be held constant during the leastsquares analysis. The other is to make full use of other methods of determining some of the transport parameters, that is by theoretical calculation or by one of the microscopic methods of measuring defect parameters. There is one microscopic technique which provides direct information about the diffusional motion of defects and that is nuclear magnetic reso- 
nance (NMR). Following a brief description of the methods used in the theoretical calculation of point defect parameters and of the NMR technique, the remainder of this paper will be devoted to a discussion of some recent examples of the analysis of transport data, stressing those in which use has been made of either theoretical calculations or NMR.

2. Theoretical calculation of point defect parameters. Only a brief description of the technique is necessary in view of the paper by Catlow [11] at this Conference. The basis of the method goes back to the calculations of Schottky and Frenkel defect energies by Mott and Littleton [12]. In a small region of the crystal that includes the defect, the interaction between the individual ions is described by an appropriate potential, but the surrounding region the crystal is treated as a dielectric continuum. There are two crucial features of the calculation. The first is the use of a potential that describes correctly the dielectric response of the crystal and here the simple shell model $[13,14]$ has been found to be both adequate [15] and manifestly superior to the older polarizable point-ion model [16]. The second important feature is the use of a sufficiently large region in which the relaxation of the ions is calculated specifically. These big regions require a large number of variables to describe the ionic positions, especially when the defect is of low symmetry, so that efficient minimization techniques are necessary $[17,18]$. These two essential features of the calculation have been implemented in the HADES program developed at the Theoretical Physics Division at Harwell $[18,19]$. This program has been widely tested in calculations on oxides [20], alkaline earth halides [21] and alkali halides [22, 23, 24]. From the results of these calculations one may conclude that, provided a suitable potential is available, the method gives reliable results.

The theoretical calculation of defect entropies has not advanced to the same stage as that of defect energies. The technique for doing such calculations is implicit in the writings of Maradudin et al. [25] and has been reformulated by Mahanty [26, 27]. The equivalence of these two approaches has been demonstrated [28] and the method has been further developed and applied to the calculation of the entropy of formation of Schottky defects in $\mathrm{KCl}$ [29] and of Frenkel defects in $\mathrm{CaF}_{2}$ [30] and $\mathrm{SrF}_{2}$ and $\mathrm{BaF}_{2}$ [31]. However, the calculation is a lengthy one, since it requires the determination of the Green's functions for the perfect crystal, and so it will likely be some time before a sufficient body of results are available for its reliability to be assessed. Nevertheless, results for $\mathrm{CaF}_{2}$ [30] are highly encouraging and a new calculation for $\mathrm{KCl}$ using a larger defect space is in progress.

3. Determination of diffusion coefficients by NMR. - The NMR method of studying ionic transport in crystals is a particularly apt one when the radioactive tracer method is difficult to apply because of the lack of a suitable isotope. An example is $\mathrm{BaF}_{2}$, for which tracer measurements have been made only over a limited temperature range at high temperature [32] but for which NMR measurements have been made, between room temperature and $1200 \mathrm{~K}$ [33]. There are two main techniques for the study of diffusion coefficients by NMR. The first involves the measurement of the relaxation times $T_{1}, T_{1 \rho}, T_{2}$, and $T_{1 D}$. $T_{1}$ is the spin-lattice relaxation time, $T_{1 \rho}$ is the spinlattice relaxation time in the rotating frame. $T_{2}$ is the spin-spin relaxation time and $T_{10}$ the relaxation time for the dipolar energy. A comprehensive perturbation theory has been developed by Wolf and Jung [34] which applies to both the weak $\left(H_{\mathrm{D}} \ll H_{1}\right)$ and strong $\left(H_{\mathrm{D}} \lesssim H_{1}\right)$ collision regions. $H_{1}$ is the radiofrequency magnetic field and $H_{\mathrm{D}}$ the local dipolar field of the nuclei. The theoretical problem of relating the measured relaxation times to a particular self-diffusion coefficient was first developed on the basis of a model in which the nuclei perform random walks on the lattice $[35,36,37]$. In the more appropriate Wolf encounter model [38] it is the encounters, or series of jumps of a single nucleus that are initiated by the presence of a point defect, which are considered to be statistically independent. This theory leads ultimately to expressions for the mean time $\tau$ between consecutive jumps of the individual ions, which may be related to the diffusion coefficient $D$ through the usual Einstein relation, modified by the inclusion of the correlation factor.

The relaxation method of determining $D$ thus depends on the existence of an adequate relaxation theory and on a knowledge of the diffusion mechanism and the jump distance. However, $D$ can be measured directly by using the pulsed field gradient (PFG) technique [40]. Two magnetic field gradient pulses are applied : the first occurs between the $90^{\circ}$ and $180^{\circ}$ radiofrequency (RF) pulses of a spin-echo sequence and the second (identical) one is applied between the $180^{\circ} \mathrm{RF}$ pulse and the spin echo. Any net displacement of the ions that occurs during the period $\Delta$ between the two PFG pulses results in a lowering of the echo amplitude relative to that observed without the gradient pulses and from the ratio of these echo amplitudes $D$ can be calculated [39].

4. Potassium chloride. - We have recently [40] measured the conductivity of nominally pure $\mathrm{KCl}$, $\mathrm{KCl}: \mathrm{Sr}^{2+}$, and $\mathrm{KCl}: \mathrm{SO}_{4}^{2-}$ over as wide a temperature as possible. These data were analyzed on the basis of several models bu the only one that lead to a consistent set of defect parameters was one that allowed for Frenkel defects on both sub-lattices, in addition to the predominant Schottky defects. This model has twenty-two parameters which have to be determined from the data for the three systems studied though two of these, the concentrations of $\mathrm{Sr}^{2+}$ and $\mathrm{SO}_{4}^{2-}$, were already known. Because it is extremely difficult 
to determine the values of parameters that control the contributions from minority carriers to the total ionic transport, the enthalpies of formation of Frenkel defects and the enthalpies of migration of cation and anion interstitials were held fixed at their calculated values $[22,23]$ and the remaining parameters determined as described in another paper at this Conference [40]. An example of the fit of the conductivity calculated using this model to the experimental measurements is shown in figure 1 . The same set of

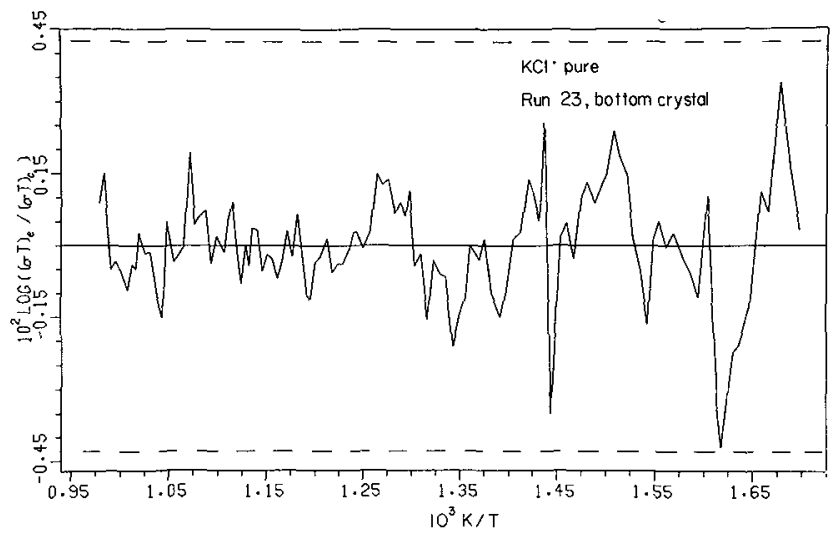

Fig. 1. - Plot of the difference between experımental and calculated values of $\log (\sigma T)$ as a function of $T^{-1}$, for pure $\mathrm{KCl}$.

parameters fits the data for all three systems equally well. Even so, several parameters are defined by ranges rather than by unique values, which means that any value of that parameter within the range shown will fit the conductivity equally well, but for a value outside the range the fitting is noticeably worse.

These parameters were then used to calculate the diffusion coefficients of $\mathrm{K}^{+}\left(\mathrm{D}_{\mathrm{c}}\right)$ in $\mathrm{KCl}, \mathrm{KCl}: \mathrm{Sr}^{2+}$ and $\mathrm{KCl}: \mathrm{SO}_{4}^{2-}$ and of $\mathrm{Cl}^{-}\left(\mathrm{D}_{\mathrm{a}}\right)$ in $\mathrm{KCl}$ and $\mathrm{KCl}: \mathrm{Sr}^{2+}$. Those parameters defined by ranges were varied through their respective ranges to determine if a single unique set of parameters that fitted all the conductivity and diffusion data for all these systems, could be obtained. This was found to be so for all parameters except the entropy of Schottky defect formation for which values in the range 7.5 to $7.9 k$ had to be used to fit the transport data for the various systems. In the calculations of $D_{\mathrm{c}}$ and $D_{\mathrm{a}}$ the enthalpy of formation of vacancy pairs and the enthalpy change for the jump of a cation or an anion into the pair were fixed at their calculated values [23] and the corresponding entropies adjusted to give reasonable agreement. An example of the calculated and experimental diffusion coefficients is shown in figure 2 .

One might question how it is that one can be sure of the existence of minority carriers such as the cation and anion interstitials. The prime reason is that the calculated Arrhenius energies for cation and anion migration by single vacancies, interstitials and vacancy pairs are all very similar, as shown in table I. For pure $\mathrm{KCl}$ the standard deviation improves by a factor of

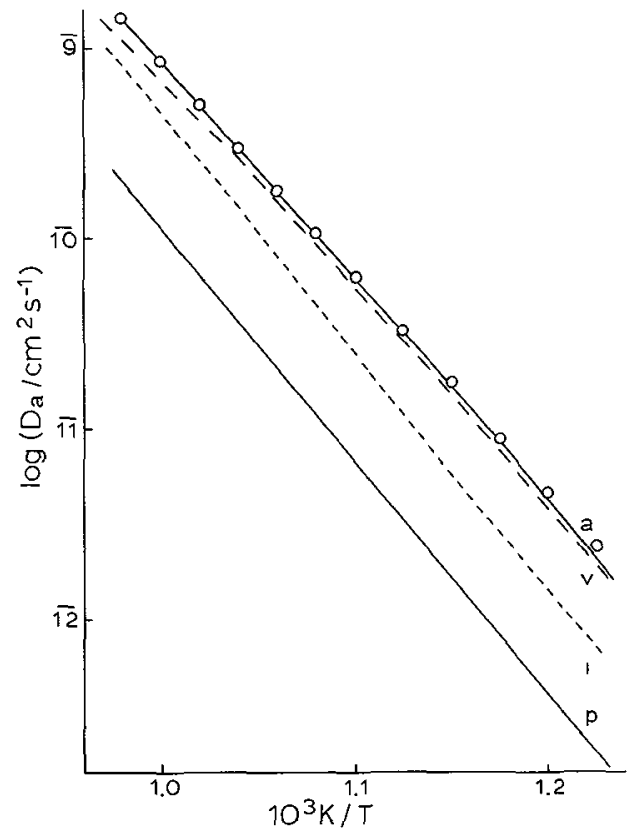

Fig. 2. - Temperature dependence of the diffusion coefficient of $\mathrm{Cl}^{-}$in pure KCl. Experimental, $\bigcirc$ [5]. Calculated : $v=D_{\mathrm{av}}$; $p=D_{\mathrm{ap}} ; i=100 \times D_{\mathrm{a}}$.

Table I. - Calculated Arrhenius energies (in eV) for ion transport in $\mathrm{KCl}$.

Vacancies

Cation

Anion

Interstitials

1.98

1.97

2.19

2.14

Vacancy pairs

2.32

2.33

10-50 if the conventional Schottky model is modified to include interstitials on both sub-lattices. For $\mathrm{KCl}: \mathrm{Sr}^{2+}$ Fuller [41] long ago observed an unexpected effect : at high $\mathrm{Sr}^{2+}$ concentrations the isothermal diffusion coefficient of $\mathrm{Cl}^{-}$increases with increasing $\mathrm{Sr}^{2+}$ content, instead of remaining constant, as expected from the Schottky model. That this effect is a consequence of the increase in the anion Frenkel defect concentration as a result of doping with $\mathrm{Sr}^{2+}$, is shown by the calculated diffusion coefficients in figure 3.

5. Silver chloride. - The conductivity of both $\mathrm{AgCl}$ [42] and $\mathrm{AgBr}$ [43] exhibit rather famous anomalies at high temperatures. If the fitting of the defect parameters is carried out using the conventional Frenkel defect model, without any constraints, the excess conductivity is allocated to the minority carriers which are $\mathrm{Ag}^{+}$interstitials migrating by the non-collinear interstitialcy (inc) mechanism, and unrealistically high inc migration parameters result [8]. If constraints are imposed by fixing the vacancyinterstitial mobility ratio and the ratio of the jump frequencies for the collinear and non-collinear interstitialcy mechanisms [42, 43] then the anomalous 


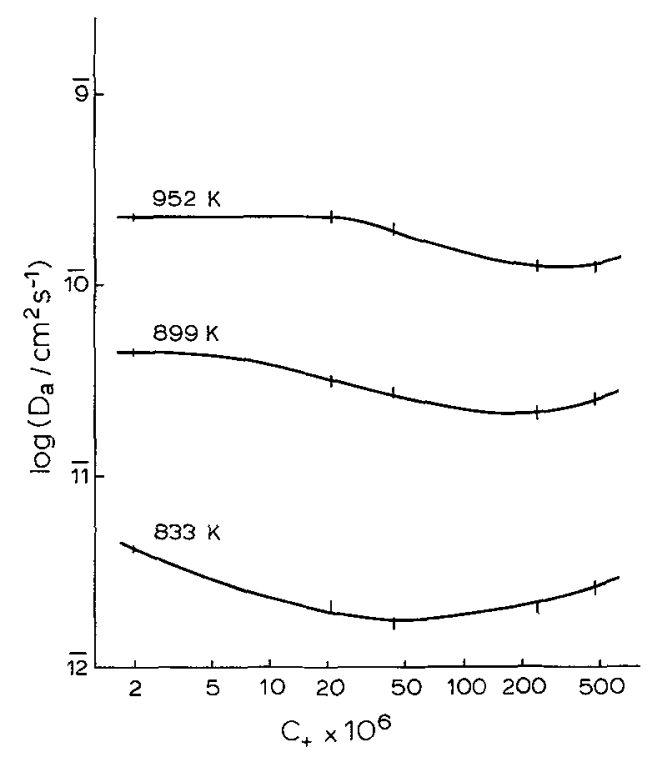

Fig. 3. - Dependence of the diffusion coefficient of $\mathrm{Cl}^{-}$in $\mathrm{KCl}$ on the concentration $c_{+}$of $\mathrm{Sr}^{2+}$ ions. Vertical bars, experimental results [41]; continuous lines, calculated.

conductivity increase at high temperatures is seen to be due to an extra temperature-dependent decrease $\left(\Delta g_{\mathrm{ex}}\right)$ in the Gibbs free energy of formation $\left(g_{\mathrm{F}}\right)$ of the Frenkel defects in addition to that from the $T s_{\mathrm{F}}$ term, where $s_{\mathrm{F}}$ is the (constant) non-configurational entropy of formation of a Frenkel defect pair. That the anomalous conductivity increase is indeed due to the temperature-dependence of the Frenkel-defect formation energy, rather than to anomalous changes in ionic mobility or to the onset of new transport mechanisms, was shown by the linearity of the Arrhenius plot of $\log \left(D_{\mathrm{Na}^{+}} / c\right)$ vs. $T^{-1}$, where $D_{\mathrm{Na}^{+}}$ is the diffusion coefficient of $\mathrm{Na}^{+}$in $\mathrm{AgCl}$ and $c_{v}$ is the concentration of cation vacancies [44]. This shows unambiguously that the anomalous increase in $D_{\mathrm{Na}^{+}}$at high temperatures (as shown by the upward curvature of the usual Arrhenius plot, $\log D_{\mathrm{Na}}+$ vs. $T^{-1}$ ) is caused by the increased concentration of cation vacancies due to $\Delta g_{\mathrm{ex}}$ and not by large changes in the activation energy for the migration of $\mathrm{Na}^{+}$ions by the cation vacancy mechanism. We therefore calculated the Frenkel defect formation energy $u_{\mathrm{F}}$ as a function of $T$ using the quasiharmonic model [45]. The results showed that $u_{\mathrm{F}}$ indeed decreases with $T$ from $1.361 \mathrm{eV}$ at $50^{\circ} \mathrm{C}$ to $1.122 \mathrm{eV}$ at $450{ }^{\circ} \mathrm{C}$. When the calculated Frenkel energies are used along with experimental mobility parameters [42] to calculate the conductivity of $\mathrm{AgCl}$, this is seen to be in excellent agreement with the experimental curve [46], thus confirming that the original anomaly is indeed due to an extra decrease in $g_{\mathrm{F}}$ with $T$, and showing that $\Delta g_{\text {ex }}$ is due to a decrease in the Frenkel defect formation energy while $s_{\mathrm{F}}$ remains approximately constant. We also calculated the diffusion coefficient of $\mathrm{Na}^{+}$ in $\mathrm{AgCl}$ using our calculated formation energies, the calculated value for the migration energy of $\mathrm{Na}^{+}$ in $\mathrm{AgCl}, \Delta u_{\mathrm{Na}}+(\mathrm{T})$, and the constant value of $s_{\mathrm{F}}$ $(4.72 \mathrm{k})$ that fits the conductivity. As shown in figure 4 the results agree excellently with Batra and Slifkin's experimental values [44]. I should perhaps comment on the constancy of $s_{\mathrm{F}}$ with $T$. At first one might expect that if $u_{\mathrm{F}}$ depends on $T$, so much $s_{\mathrm{F}}$ through the thermodynamical relation

$$
\mathrm{d} s_{\mathbf{F}} / \mathrm{d} t=(1 / T)\left(\mathrm{d} h_{\mathbf{F}} / \mathrm{d} T\right)
$$

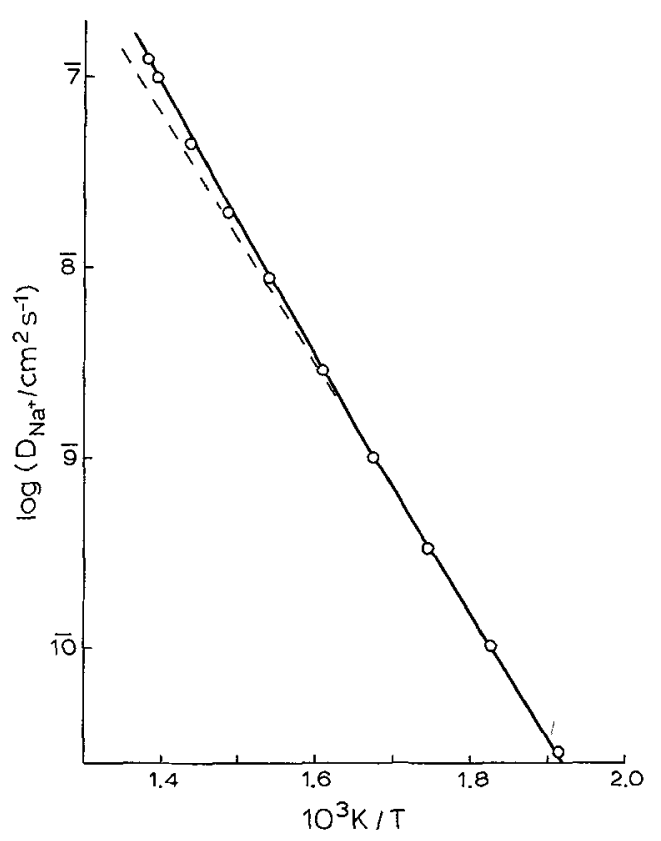

Fig. 4. - Temperature dependence of the diffusion coefficient of $\mathrm{Na}^{+}$in $\mathrm{AgCl}$. Circles show experimental data of Batra and Slifkin [44]. The continuous line was calculated as described in the text. The dashed line is a linear extrapolation of the low-temperature data.

since $h_{\mathrm{F}} \simeq u_{\mathrm{F}}$ for condensed phases at ordinary pressures. If the applicability of eq. (1) were to be assumed then $s_{\mathrm{F}}$ would change by $\sim 5 k$ between room temperature and $450^{\circ} \mathrm{C}$, a change which seems far too large. No calculations of $s_{\mathrm{F}}$ have been done yet for $\mathrm{AgCl}$ but we have recently [31] calculated the temperature dependence of $s_{\mathrm{F}}$ for anion Frenkel defects in $\mathrm{CaF}_{2}$ in the quasiharmonic approximation and find that this is rather small : $s_{\mathrm{F}}$ increases by only $6.8 \%$ between 300 and $1500 \mathrm{~K}$. The solution to the dilemma appears to be that the temperaturedependent defect formation energy calculated from the HADES program in the quasiharmonic approximation is not a thermodynamical enthalpy, since it results from a minimization of the potential energy of the crystal rather than its free energy. Thus it would be thermodynamically inconsistent to apply eq. (1) to our calculated energies and the unrealistically large changes in $s_{\mathrm{F}}$ with $T$ that result from sodoing is a confirmation that quasiharmonic HADES defect energies should be used with constant defect entropies until such time as the results of calculations 
for $s(T)$ become available. We also calculated [48] the diffusion coefficient of the anion in $\mathrm{AgCl}$, using theoretical values for the migration energy of single anion vacancies and for the binding energy of a vacancy pair. The result [48] is in rather good agreement with the experimental results of Batra and Slifkin [47].

Encouraged by the success of our potential in predicting the correct variation of the Frenkel formation energy with $T$ we then calculated some cation migration energies with at first rather alarming results. The values for cation vacancy motion and cation interstitialcy collinear motion, two energies whose values were well-known from experiment [8, 42], came out much too high. Consideration of this problem led to the conclusion that the $\mathrm{Ag}^{+}$ion undergoes a quadrupolar deformation as it migrates in to the saddle point configuration. Inclusion of this deformation in the calculation $[45,48]$ resulted in a striking agreement between the calculated and experimental values, provided the quadrupolar force constant $K_{\mathrm{Q}}$ was about $0.5 \mathrm{eV} \AA^{-2}$, which is just the value (0.5-0.6 eV $\left.\AA^{-2}\right)$ indicated by an analysis of phonon dispersion in $\mathrm{AgCl}$ [49].

6. Fluorites. - The most complete study of transport processes in an ionic crystal by both macroscopic and microscopic techniques is that on $\mathrm{BaF}_{2}$ by Figueroa, Chadwick and Strange [33] who measured ionic conductivity and the ${ }^{19} \mathrm{~F}$ NMR relaxation times $T_{1}$, $T_{2}, T_{1 \rho}$ or $T_{1 \mathrm{D}}$ over the temperature range $300-$ $1200 \mathrm{~K}$. We have recently [50] analyzed the conductivity of $\mathrm{BaF}_{2}$ and on using appropriate values of $D_{\mathrm{v}} / D_{1}$ calculated from the transport numbers at low and high temperatures (with due allowance for the Haven ratios) it turns out that $D_{\mathrm{F}^{-}}^{\mathrm{NMR}} / D_{\mathrm{F}}^{\sigma}$ - is about 1.3. This discrepancy is removed if $D_{\mathrm{i}}^{\text {NMR }}$ is divided by a factor of 1.5. This is seen more directly from the measurements in the extrinsic region of $\mathrm{BaF}_{2}: \mathrm{La}^{3+}$ where $D^{\mathrm{NMR}} / D^{\sigma}$ is about 1.5 [33]. Figueroa et al. were unable to pin-point the source of this discrepancy which they felt must lie in the theoretical interpretation using the encounter model but may be due to some unexplained feature of the NMR results. However, the enthalpies of formation and migration of the Frenkel defects derived from NMR are in excellent agreement with those obtained from conductivity. Since the former measures the relaxation time for ionic jump frequencies on an atomic scale, while the latter measures the bulk motion of defects averaged over many jumps, this coincidence in the derived energies and the near agreement in the absolute values of $D$ is of considerable importance to the general theory of transport processes in ionic crystals. Recently, the diffusion coefficient of $\mathrm{F}^{-}$ions in $\mathrm{PbF}_{2}$ has been measured at high temperatures by the PFG method by Gordon and Strange [51]. These measurements are in excellent agreement (given the experimental difficulties in this temperature range) with the conductivity measurements of Carr, Chadwick and Saghafian [52]. A reconcilation of the two sets of data requires a value for the Haven ratio $H_{\mathrm{r}}$ of between 0.7 and 1.0. Since $H_{\mathrm{r}}$ is 0.653 for vacancies and 0.739 for interstitials this might be taken as evidence for a defect mechanism for ionic transport in the FIC region, a result not inconsistent with a recent molecular dynamics simulations of fluorites [53].

Acknowledgment. - I am much indebted to those former students and research associates, particularly Dr. L. A. Acuña, Dr. J. H. Beaumont, Dr. N. Brown, Dr. J. Corish, Dr. S. H. Ong and Dr. P. Pantelis, whose painstaking measurements and data analysis have contributed so much to present understanding of transport processes in ionic crystals.

\section{DISCUSSION}

Question. - A. D. Le Claire.

Have you calculated the temperature dependence of the Schottky parameters for $\mathrm{KCl}$ to see if such a dependence might obviate the need to introduce interstitials to optimise the interpretation of transport data.

\section{Reply. - P. W. M. JACOBS.}

Yes, we did calculate this temperature dependence. Although it leads to a slight improvement over the conventional Schottky defect model with constant parameters, it does not provide a satisfactory fit to the data. Only the introduction of Frenkel defects does this.

Question. - A. B. LIDIARD.

You use the results of Batra and Slifkin on $\mathrm{Na}^{+}$ diffusion in $\mathrm{AgCl}$ to conclude that the excess conductivity of $\mathrm{AgCl}$ (and $\mathrm{AgBr}$ ) is due to an enhanced concentration of Frenkel defects rather than to enhanced mobilities (or to an effect on both). But it should be pointed out that the argument assumes that the correlation factor for $\mathrm{Na}^{+}$diffusion is not dependent upon temperature. It would therefore be valuable to determine this factor by an isotope effect experiment or in other ways.

\section{Reply. - P. W. M. JACOBS.}

I believe that the curvature in Batra and Slifkin's data is too large to be accounted for by the temperature dependence of $f$, which should be close to unity.

Answer to Lidiard's comment. - L. SLIFKIN.

The correlation factor for $\mathrm{Na}^{+}$in $\mathrm{AgCl}$ must be 
very near to unity, and hence almost independent of temperature. This must be so, because the activation energy for the jump of $\mathrm{Na}^{+}$is much larger than for the jump of a substitutional $\mathrm{Ag}^{+}$into a vacancy. Thus, any temperature-dependence of the correlation factor is quite small, as compared to the conductivity anomaly, which is a factor of about 2 .

\section{Question. - W. HAYES.}

Is there an anomalous expansion in $\mathrm{AgCl}$ associated with the increase in the number of defects at high temperatures.

\section{Reply. - P. W. M. JACOBS.}

The expansivity of $\mathrm{AgCl}$ is large but I would not describe it as anomalous. The measured expansivity includes the effect of the number of defects and, indeed, it is the comparison of expansivity with lattice parameter change that led Fouchaux and Simmons to conclude that the majority of defects were Frenkel defects.

\section{Question. - F. GRANZER.}

I am a little astonished that you could obtain reliable values for the formation energies of Frenkel defects in silver halides with calculations based on the HADES program. To my knowledge this program cannot properly take into account interaction potentials which describe the peculiar physical properties of the silver halides in an appropriate way.

\section{Reply. - P. W. M. JACOBS.}

It is true that our potential is a two-body one and therefore cannot describe the large Cauchy violation in $\mathrm{AgCl}$. However, we set out to see if a two-body potential could give accurate defect energies for $\mathrm{AgCl}$. It seems that the crucial feature is a large $\mathrm{Ag}^{+}-\mathrm{Ag}^{+}$ van der Waals interaction which stabilizes the $\mathrm{Ag}^{+}$ interstitials. The $\mathrm{Ag}^{+}-\mathrm{Cl}^{+}$van der Waals coefficient is also large.

References

[1] Lidiard, A. B., Handb. Phys. 20 (1957) 246.

[2] Fredericks, W. J., Diffusion in Solids ed. Nowick A. S. and Burton J. J. (Academic Press, New York) (1975), chap. 8.

[3] Patterson, D., Rose, G. S. and Morrison, J. A., Philos. Mag. 1 (1956) 393.

[4] Beaumont, J. H. and Jacobs, P. W. M., J. Chem. Phys. 45 (1966) 1946.

[5] Bénikire, M., Chemla, M. and BÉnière, F., J. Phys. Chem. Solids 37 (1976) 525.

[6] JACOBS, P. W. M. and ONG, S. H., J. Physique Colloq. 37 (1976) C7-331.

[7] Jacobs, P. W. M. and Pantelis, P., Phys. Rev. B 4 (1971) 3757.

[8] CoRish, J. and JACOBs, P. W. M., J. Phys. Chem. Solids 33 (1972) 1799.

[9] Carr, V. M., Chadwick, A. V. and Figueroa, D. R., J. Physique Colloq. 37 (1976) C7-337.

[10] Brown, N. and JACOBS, P. W. M., J. Physique Colloq. 34 (1973) C9-437.

[11] Catlow, C. R. A., J. Physique Colloq. 40 (1979).

[12] Motr, N. F. and Littleton, M. J., Trans. Faraday Soc. 34 (1938) 485.

[13] Dick, B. G. and Overiauser, A. W., Phys. Rev. 112 (1958) 90.

[14] Cochran, W., Crit. Rev. Solid State Sci. 2 (1971) 1.

[15] FauX, I. D. and Lidiard, A. B., Z. Naturforsch. a 26 (1971) 62

[16] Boswarva, I. M. and Lidiard, A. B., Philos. Mag. 16 (1967) 805 .

[17] Norgett, M. J. and Fletcher, R., J. Phys. C : Solid St. Phys. 3 (1970) L 190.

[18] Lidiard, A. B. and NorgetT, M. J., Computational Solid State Physics ed. Herman, F., Dalton, N. W. and Koehler, T. R. (Plenum, New York) (1972), p. 385.

[19] Norgett, M. J., AERE Harwell Rep. R 7650 (1974).

[20] Catlow, C. R. A., Faux, I. D. and Norgett, M. J., J. Phys. C : Solid St. Phys. 9 (1976) 419.

[21] Catlow, C. R. A. and Norgett, M. J., J. Phys. C : Solid St. Phys. 6 (1973) 1325.

[22] Catlow, C. R. A., CoRish, J., Diller, K. M., Jacobs, P. W. M. and NorgetT, M. J., J. Physique Colloq. 37 (1976) C7-253

[23] Catlow, C. R. A., Corish, J., Diller, K. M., Jacobs, P. W. M. and NorgetT, M. J., J. Phys. C. Solid State Phys. 12 (1979) 451.

[24] Catlow, C. R. A., Corish, J., Diller, K. M., Jacobs, P. W. M. and Norgert, M. J., Phys. Rev. B 18 (1978) 2739.

[25] Maradudin, A. A., Montroll, E. W., Weiss, G. H. and IPATOVA, I. P., Theory of Lattice Dynamics in the Harmo- nic Approximation Solid State Phys. Suppl. 3 (Academic Press, New York) 2nd ed. (1971).

[26] Mahanty, J., Phys. Lett. 29A (1969) 583.

[27] Mahanty, J. and Sachdev, M., J. Phys. C. Solid St. Phys. 3 (1970) 773.

[28] Govindarajan, J., Jacobs, P. W. M. and Nerenkerg, M. A., J. Phys. C. Solid St. Phys. 9 (1976) 3911.

[29] Govindarajan, J., Jacobs, P. W. M. and Nerenberg, M. A., J. Phys. C. Solid St. Phys. 10 (1977) 1809.

[30] Haridasan, T. M., Govindarajan, J., Nerenberg, M. A. and $J_{A C O B S}$, P. W. M., Phys. Rev. B (1979) in the press.

[31] Haridasan, T. M., Govindarajan, J., NerenberG, M. A. and JACOBS, P. W. M., to be published.

[32] Matzke, H., J. Mater. Sci. 5 (1970) 831.

[33] Figueroa, D. R., Chadwick, A. V. and Strange, J. H., $J$. Phys. C. Solid St. Phys. 11 (1978) 55.

[34] Wolf, D. and Jung, P., Phys. Rev. 12 (1975) 3596.

[35] Sholl, C. A., J. Phys. C. Solid St. Phys. 7 (1974) 3378.

[36] Sholl, C. A., J. Phys. C. Solid St. Phys. 8 (1975) 1737.

[37] Wolf, D., J. Magn. Reson. 17 (1975) 1.

[38] WOLf, D., Phys. Rev. 10 (1974) $2710 ; 2724$.

[39] Stejskal, E. O. and Tanner, J. E., J. Phys. Chem. 42 (1965) 288.

[40] ACUÑA, L. and JACOBs, P. W. M., J. Physique Colloq. 40 (1979).

[41] Fuller, R. G., Phys. Rev. 142 (1966) 524.

[42] Aboagye, J. K. and Friauf, R. J., Phys. Rev. B 11 (1975) 1654.

[43] Friauf, R. J., J. Physique 38 (1977) 1077.

[44] Batra, A. P. and Slifkin, L. M., Phys. Rev. B 12 (1975) 3473.

[45] Catlow, C. R. A., Corish, J., Devlin, B. A. and Jacobs, P. W. M., Proc. Conf. on Fast Ion Transport in Solids, Lake Geneva, Wisconsin, U.S.A., May 1979.

[46] Catlow, C. R. A., Corish, J. and Jacors, P. W. M., J. Phys. C. Solid St. Phys. (1979) in the press.

[47] Batra, A. and Slufkin, L. M., J. Phys. C. Solid St. Phys. 9 (1976) 947.

[48] JACobs, P. W. M., Corish, J. and Catlow, C. R. A., to be published.

[49] Kleppmann, W. G., J. Phys. C. Solid St. Phys, 9 (1976) 2285.

[50] JACOBS, P. W. M. and ONG, S. H., to be published.

[51] Gordon, R. E. and Strange, J. H., J. Phys. C. Solid St. Phys. 11 (1978) 3213.

[52] Carr, V. M., Chadwick, A. V. and Saghafian, R., J. Phys. C. Solid St. Phys. (1979).

[53] Drxon, M. and Gillan, M. J., J. Phys. C. Solid St. Phys. 11 (1978) L 165. 